\title{
IMPACTO DEL OZONO TROPOSFÉRICO SOBRE LA ANATOMÍA FOLIAR DE ABIES PINSAPO BOISS. I: ESTUDIO DE LA DISTRIBUCIÓN DE DAÑOS
}

\author{
David LÁZARO-GIMENO* y Ana M. IBARS \\ Laboratorio de Anatomía e Histología Vegetal "Julio Iranzo”, Jardín Botánico, \\ Universitat de Valencia, ICBiBE. \\ *Autor para correspondencia: david.lazaro-gimeno@uv.es
}

Recibido el 26 de mayo de 2008, aceptado para su publicación el 11 de noviembre de 2008

Publicado "on line" en marzo de 2009

\begin{abstract}
RESUMEN. Impacto del ozono troposférico sobre la anatomía foliar de Abies pinsapo Boiss. I: Estudio de la distribución de daños. Con el fin de elaborar unos criterios unificados para la evaluación del impacto del ozono troposférico y compararlos con la respuesta de las poblaciones naturales de Sierra Bermeja y Sierra de las Nieves, se han reproducido en cámaras Open Top, ambientes filtrados y enriquecidos con ozono para realizar una caracterización microscópica del daño que produce el ozono troposférico sobre Abies pinsapo Boiss. Los resultados demuestran que pese a que la morfología foliar permanece inalterada tras someter durante un mes en condiciones de $30 \mathrm{ppb}$ durante 8 horas al día, a nivel tisular se han producido daños de consideración que afectan de este endemismo.
\end{abstract}

Palabras clave. Anatomía, Abies pinsapo, ozono, cámaras Open Top.

ABSTRACT. Tropospheric ozone injury on the foliar anatomy of Abies pinsapo Boiss. I: Study of damage distribution. With the aim of develop unified criteria to evaluate the tropospheric ozone injury and compare with responses in Abies pinsapo Boiss. in natural populations in Sierra Bermeja and Sierra de las Nieves, it has been reproduced in Open Top Chambers conditions of filtered air and addition of controlled amounts of ozone. Results show that despite leaf morphology remains unaltered after a treatment with $30 \mathrm{ppb} 8$ hours per day, at tissue level there have been injuries that affect this endemism.

Key words. Anatomy, Abies pinsapo, ozone, Open Top chambers.

\section{INTRODUCCIÓN}

Los fotooxidantes, y especialmente el ozono, han sido considerados como dañinos para la vegetación desde 1980 en Europa. Se habla del ozono como un contaminante secundario, debido a su origen, y sin embargo sus efectos sobre las masas forestales pueden ser considerados como de primer orden. Por ello continuamente se van mejorando los métodos 
para conocer la distribución del ozono tanto a nivel global como a nivel local (Cuevas et al, 1996, Fishman et al, 2003).

La recepción de material vegetal de Abies pinsapo Boiss. y su estudio inicial, mediante el uso de microscopia electrónica de barrido, indicaron que existía un daño en las acículas, pero no se podía determinar las causas. Parte del material fue procesado para su observación con microscopia óptica y los resultados preliminares destacaron patrones de comportamiento similares a los producidos por el efecto del ozono en otros táxones (GünthardGoerg and Vollenweder, 2007; Reig-Armiñana et al, 2004).

En el presente trabajo se muestran los primeros datos sobre el estado de conservación de las masas forestales de Abies pinsapo Boiss. en Sierra Bermeja y Sierra de las Nieves, como parte de un estudio a largo plazo de estos bosques y sobre cómo afecta el ozono a su biología reproductiva.

\section{OBJETIVOS}

Los objetivos del presente trabajo se estructuran en dos partes principales: en primer lugar realizar una prospección de la distribución de daños foliares en Abies pinsapo, con la reproducción de un ambiente con cantidades de ozono controlado para realizar una caracterización de los daños, estableciendo criterios unificados de evaluación de daños foliares. Seguidamente, los resultados se compararon con muestras tomadas de las poblaciones naturales para determinar el nivel de afectación.

\section{METODOLOGÍA}

A partir de semillas de las poblaciones naturales se obtuvieron plántulas con hojas que estuviesen en su primer año de crecimiento y hojas en segundo año. La distinción entre hojas de ambos tipos se basó en el hecho que los pinsapos tienen sólo una época de crecimiento al año, de manera que cada verticilo corresponde a un año de vida de la plántula (Arista et al, 1997). Cuatro alvéolos forestales con las plántulas fueron llevadas a la Granja Experimental La Peira, propiedad del Centro de Estudios Ambientales del Mediterraneo (CEAM), en el término municipal de Benifaió, a 20 kilómetros de Valencia, emplazada en $39^{\circ} 16^{\prime} 14.8^{\prime \prime} \mathrm{N}, 00^{\circ} 26^{\prime} 59^{\prime}$ 'W y 30 metros de altitud sobre el nivel del mar, para ser sometidas a tratamiento con aire filtrado $\mathrm{y}$ aire enriquecido con ozono. Dos plántulas fueron introducidas en una cámara Open Top (OTC), de tipo NCLAN, en las cuales el aire fue filtrado mediante el uso de dispositivos con filtros con carbono activo. Otras dos plántulas fueron introducidas en cámaras en la cuales el ambiente fue enriquecido con $30 \mathrm{ppb}$ de $\mathrm{O}_{3}$ durante 8 horas al día. En los intervalos de 15 días y 1 mes se tomaron muestras de acículas de primer y segundo año. Una de las réplicas fue fijada en F.A.A. (formol-acético-alcohol, Johansen, 1940) y la otra en un fijador de tipo Karnoski (mezcla de glutaraldehido y paraformaldehido) al 4\% durante 8 horas, esta última neutralizada con tampón fosfato de Sorenson 0.1 M pH 7.2.

Para la obtención de muestras foliares de las poblaciones naturales se siguió un gradiente altitudinal desde los 930 metros hasta los 1700 metros en Sierra Bermeja y Sierra de las Nieves (tab. 1). Se obtuvieron ramas con acículas en primer y segundo año de crecimiento que fueron fijadas en F.A.A.

Todas las muestras fueron deshidratadas siguiendo series de etanol crecientes. Una vez llegado a este punto, las muestras fijadas en F.A.A. fueron procesadas según los procedimientos de obtención de secciones en parafina con un grosor de 10-12 $\mu \mathrm{m}$. Las muestras fijadas en Karnoski fueron infiltradas en resina LR White Medium Grade (London Resins) y 


\begin{tabular}{llll}
\hline Localidad & UTM & Altitud & Fecha recolección \\
\hline Genalguacil. Arroyo del Algarrobo. & $302954 \mathrm{E}$ & 930 & $23 / 06 / 2005$ \\
Carril de las Alberquillas & $4041569 \mathrm{~N}$ & & \\
Yunquera. Pinsapar Saucillo & 30 SUF2265 & 1100 & $10 / 05 / 2005$ \\
Genalguacil. Paseo de los Pinsapos & $302985 \mathrm{E}$ & 1180 & $23 / 06 / 2005$ \\
& $40400894 \mathrm{~N}$ & & \\
Yunquera. Pinsapar Saucillo & 30 SUF2265 & 1350 & $10 / 05 / 2005$ \\
Parauta & $317609 \mathrm{E}$ & 1440 & $10 / 05 / 2005$ \\
& $4057850 \mathrm{~N}$ & & \\
Casares. Los Reales Sierra Bermeja & $302339 \mathrm{E}$ & 1450 & $23 / 06 / 2005$ \\
& $4040208 \mathrm{~N}$ & & $10 / 05 / 2005$ \\
Puerto de los Quejigales & $30 \mathrm{SUF} 1863$ & 1500 & $10 / 05 / 2005$ \\
Puerto Pilones & $322153 \mathrm{E}$ & 1700 & \\
\hline
\end{tabular}

Tabla 1. Lista de localidades en las que se realizó la recolección de muestras en Sierra de las Nieves y Sierra Bermeja siguiendo un gradiente altitudinal.

posteriormente polimerizadas, obteniéndose secciones de 1-1.5 $\mu \mathrm{m}$. Una fracción de todas las muestras fue aclarada con agua destilada para la obtención de secciones utilizando un microtomo de congelación. Se seleccionaron aquellas más adecuadas para realizar tinción una solución Yodo Yodurada de lugol, que evidencia la presencia de almidón en los plastos. Otra parte se sometió a una tinción con Azul de Anilina para su posterior observación bajo microscopio con luz ultravioleta, con una longitud de onda de excitación de $360 \mathrm{~nm}$.

De las secciones que se obtuvieron mediante el uso de microtomo de parafina, una parte se tiñeron con Safranina-Verde Rápido, la otra mediante tinción triple con Astra Blue, Rojo Neutro y Naphtol Yellow. Se trata de una alternativa a una tinción triple para la detección de lípidos (Brundrett et al, 1992).

Así mismo, se prepararon muestras para hacer un estudio de las superficies con microscopía electrónica de barrido, siguiendo la metodología usual para ello.

Finalmente las secciones semifinas que se obtuvieron de las muestras infiltradas en resina se tiñeron mediante el colorante Azul de Toluidina.

Una vez procesadas las muestras se observaron en un microscopio Olympus AT70TF con fuente de iluminación en epifluorescencia Olympus U-ULS 100 HG además de una cámara para la realización de fotografía digital Olympus C-2000 Zoom.

Las fotos fueron calibradas mediante la adquisición de imágenes de una escala micrométrica Olympus OB-M 1/100 a los diferentes aumentos que se realizaron las fotos: 10x, 20x, 40x, 100x. Para ello se empleó el software Adobe Photoshop CS al que se le añadió el plug-in Ipage Processing Tool Kit 5 para análisis de imagen.

\section{RESULTADOS}

\section{Anatomía de la hoja de Abies pinsapo no alterada}

Muestra una cutícula gruesa de naturaleza cérea y por debajo una epidermis de células redondeadas con pared secundaria poco desarrollada. Presenta un lumen celular reducido y ocupado por sustancias de naturaleza terpé- 
nica (fenoles), muy afines a la Safranina. La subepidermis presenta células redondeadas de mayor tamaño y de gruesa pared celulósica. El lumen celular está ocupado en menor medida por sustancias análogas a las que ocupan las células de la epidermis.

En el estrato inferior encontramos un mesófilo organizado en un parénquima en empalizada de células con grueso diámetro siendo biestratificado en la zonas alejadas del haz vascular y monoestratificado en las próximas. Sus células están ocupadas por una vacuola central con un material translúcido en las áreas centrales y material de naturaleza fenólica en el contorno que aumenta a medida que envejece la hoja, y rodeado en la periferia por una gran cantidad de cloroplastos discoidales, uniformes y de pequeño tamaño (fig. 1A).

Por debajo del parénquima en empalizada encontramos una zona de transición formada por células con vacuolas que albergan sustancias de naturaleza lipídica que tienden a agregarse.

El parénquima lagunar, por debajo de la zona de transición, presenta pocos espacios para la circulación de gases. Son células delgadas con pared primaria y contenido semejante al del parénquima de transición, si bien la cantidad de éstas no es regular. El contenido en cloroplastos es sensiblemente inferior al del parénquima en empalizada, presentando además un diámetro menor (fig. 1B).

La epidermis del envés es monoestratificada con cutícula desarrollada aunque en menor medida que en la epidermis del haz.

Existe presencia de estomas tetracíclicos tanto en la cara adaxial como en la abaxial, siendo los primeros poco funcionales.

La zona central está rodeada por una vaina monoestratificada formada por células sin Banda de Caspari. En su interior se encuentra el haz vascular acompañado de un parénquima de transfusión formado por células mesenquimáticas con contenido en material resinífero, células con vacuolas de contenido acuoso y fibras lignificadas de pared delgada con contornos deformados.

Los haces del xilema se disponen en posición adaxial, estando constituidos por un conjunto de traqueidas de escaso diámetro en la zona cercana al floema y de mayor diámetro en la zona periférica. El floema se dispone en filas radiales de células cribosas alternando con células albuminíferas que albergan en su seno contenido resinífero. Las células más viejas situadas en la zona periférica aparecen completamente colapsadas (fig. 1C).

En las proximidades del margen foliar se sitúan dos conductos resiníferos formados por una capa de células de transición con paredes mucho más desarrolladas que el resto que aíslan el contenido de los parénquimas presentes a su alrededor. En la zona interior hay un estrato de células secretoras que van perdiendo su contenido a medida que lo vierten en la luz del conducto.

\section{Anatomía de la hoja de Abies pinsapo fumi- gada en cámaras Open Top}

Los ejemplares de $A$. pinsapo tratados en cámaras OTC con 30 ppb de ozono, más el ambiental, presenta una serie de alteraciones características debidas a la acción oxidante de dicho gas (fig. 2A). Tras 15 días de exposición, se observa que la cutícula sufre una ligera degeneración, el contenido en polifenoles en la epidermis se torna muy denso y aparecen formaciones bandeadas como en pilas de sacos que separan el contenido vacuolar con una transformación característica semejante a la descrita para Pistacia lentiscus (ReigArmiñana et al., 2004). La lámina media de las células del parénquima en empalizada es sensible a los agentes oxidantes, es degradada por oxidación, por ello las células se separan y comienzan a sufrir deformaciones al alterarse también la celulosa de la pared primaria, que se desprende poco a poco en pequeñas gotas $\mathrm{y}$ va adelgazando.

En hojas de un año se ha podido observar 

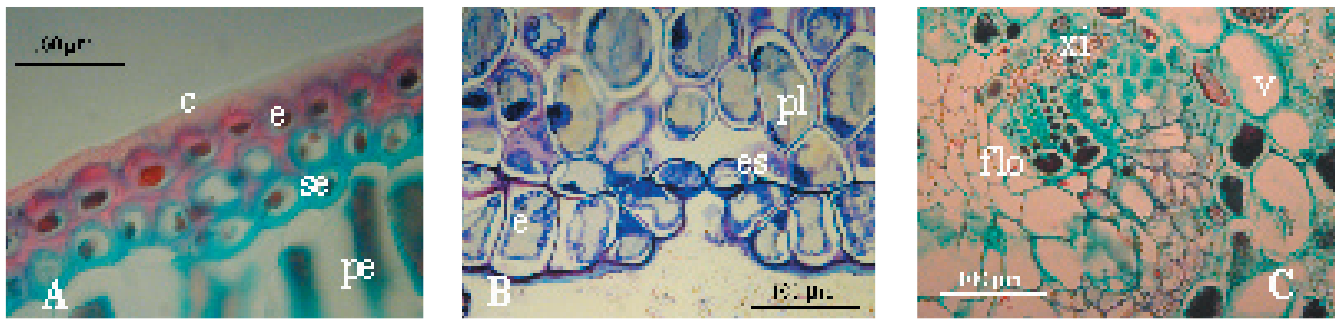

Figura 1. Secciones Abies pinsapo sometidas a aire filtrado empleadas como control. A, vista detalle superficie adaxial. B, superficie abaxial. C, organización de los haces conductores. Cutícula (c), epidermis (e), subepidermies (se), parénquima en empalizada (pe), parénquima lagunar (pl), estoma (es), vaina (v), xilema (xi), floema (flo).
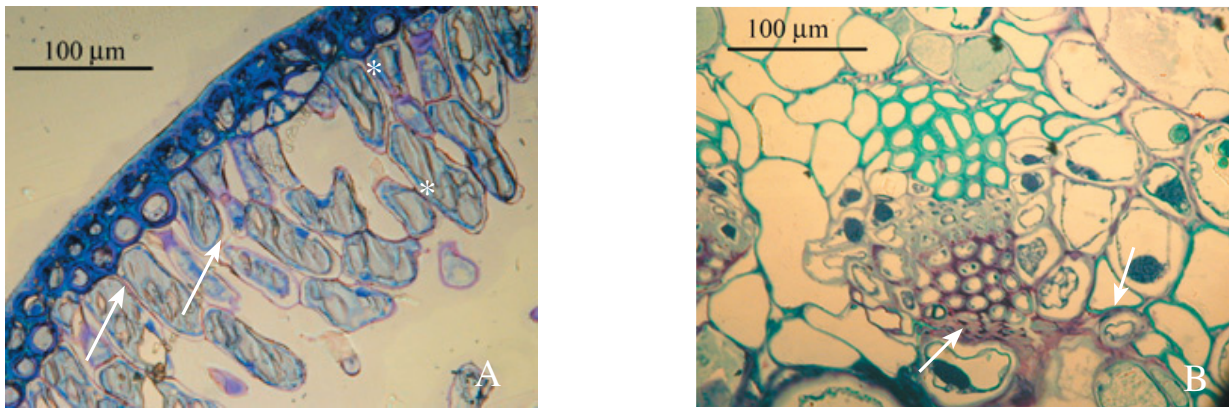

Figura 2. Daños producidos por efecto del ozono. A, sobre el tejido parenquimático: degradación de la lámina media (flecha), fragmentación de la vacuola central $(*)$, muerte celular. B, sobre el haz vascular: colapso del floema y alteraciones en células adyacentes (flechas) mientras los haces xilemáticos se mantienen sin mostrar daños.
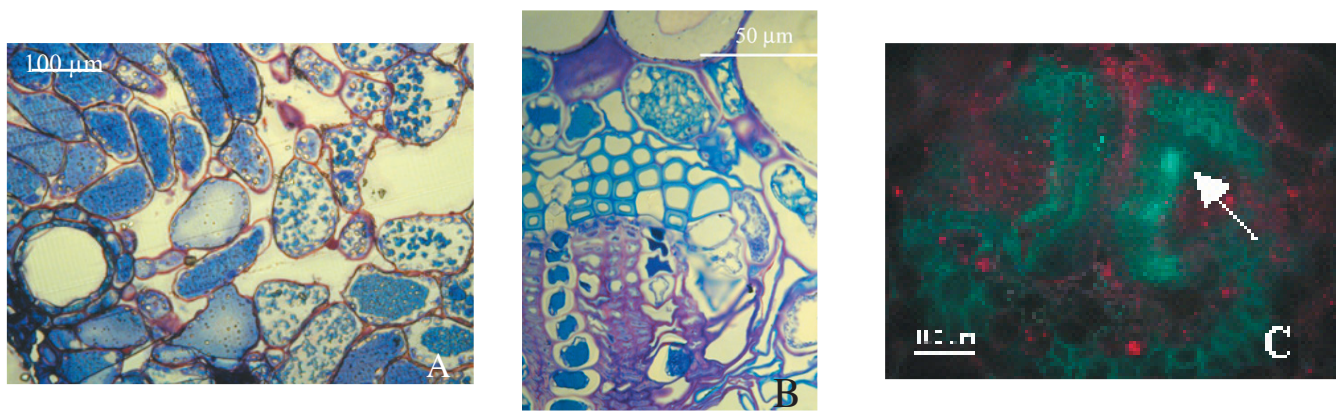

Figura 3. Efecto producido por el ozono en acículas de dos años. A, alteración de la pared celular (tonalidades rojizas), cambio en la composición del contenido celular y fragmentación de la vacuola. B, daños en haces vasculares y parénquima acumulador de agua. C, detalle de la deposición de calosa en elementos del floema, que disminuye el transporte de elaborados por sus células. 
cómo se ha producido la formación y acumulación de gránulos de almidón. El contenido vacuolar sufre un proceso semejante al descrito para la epidermis, mientras que el parénquima lagunar sufre daños similares al parénquima en empalizada: la lámina media y la pared primaria se degradan apareciendo sinuosidades en la pared celular que dejan grandes espacios entre sí, notablemente mayores en las inmediaciones de los estomas. En ellos se observa un cambio en el contenido celular, con la aparición de granulaciones. En las zonas adyacentes a las paredes degeneradas se forman unos microcristales que, además, presenta un cambio de tonalidad no apreciable en hojas filtradas.

Los haces vasculares no muestran alteraciones histológicas significativas en hojas sometidas a periodos cortos de exposición al ozono (15 días). El xilema mantiene su estructura, mientras que el floema presenta un ligero aplanamiento de sus células (fig. 2B).

A mayores tiempos de exposición sí existe colapso. Las células acompañantes sí que muestran un cambio en el contenido vacuolar, que aparece con un aspecto granulado y las células del tejido de transfusión empiezan a deformarse y a perder su función reguladora en el intercambio de agua y sustancias. La degeneración del mesófilo aumenta cualitativamente. Desaparece el contenido vacuolar de polifenoles, los plastos están fuertemente degradados y los gránulos de almidón se agrupan en otros de mayor tamaño, presentando un color más intenso al aplicarle la solución de lugol. Las células adquieren forma angulosa, poligonal, y la hoja apenas es funcional desde el punto de vista vegetativo.

Es llamativa la diferencia de comportamiento entre las hojas con crecimiento de primer año frente a las hojas que ya han completado un ciclo primario de crecimiento. El parénquima en empalizada de las hojas jóvenes, cuando se ve afectado por ozono, reacciona fragmentando la vacuola central y deformándose en una serie de pilas de discos inclinados según el eje mayor de la célula. Por el contrario, en las células de hojas con más de un año, se observa que el contenido de la vacuola cambia, mostrando tonalidades diferentes, marcada por el colorante Azul de Toluidina (fig. 3A). El floema acaba por colapsarse en su totalidad, al aplicar diferentes tinciones observamos un contenido denso en las vacuolas, mientras que el xilema no muestra alteraciones significativas en su estructura ni en su organización (fig. 3B). La calosa se presenta en mayor cantidad y en áreas cada vez más cercanas al xilema, al estudiar secciones teñidas con Azul de Anilina y observadas mediante microscopía de fluorescencia con excitación de 360 nanómetros (fig. 3C). En los cortes semifinos y en la misma zona presentan un floema con contenido en su mayor parte denso y la zona distal colapsada.

Las hojas viejas, de más de un año, en condiciones de fumigado con ozono presentan marcados daños a principios de la segunda semana. El proceso de senescencia se acelera y aparecen alteraciones diversas, que no obedecen a procesos de senescencia habituales. Las vacuolas de contenido denso se contraen y el tonoplasto se desprende de la pared, su contenido sufre alteraciones, presentando algunas zonas una coloración granate al teñir con Azul de Toluidina. Se observa un aumento de las granulaciones refringentes en el interior de las vacuolas de contenido denso, que en muchas células parenquimáticas llegan a ocupar más del 90\% del contenido vacuolar.

Las células sufren una contracción general, las paredes también degeneran y de ellas se desprenden microgotas de naturaleza fenólica, todo ello evidencia un aumento muy grande de los espacios intercelulares que se hace mucho más acusado en las cercanías de las cámaras subestomáticas. El aspecto de las células parenquimáticas se torna muy irregular. El floema distal (más alejado del xilema) aparece totalmente colapsado, sus células aplanadas y carentes de funcionalidad.

Los conductos resiníferos dejan también de ser funcionales por degeneración de las cé- 
lulas secretoras que desaparecen por completo y dejan en la luz del canal las células parenquimáticas subyacentes a las anteriores.

\section{Alteraciones en las muestras de hoja de Abies pinsapo tomadas en el campo}

\section{Sierra Bermeja (930 m. de altitud)}

Para acículas de primer año, se aprecian daños de cierta consideración, semejantes a los de una planta mantenida más de un mes en cámara. Especialmente en los parénquimas en empalizada y lagunar, donde resaltan los grandes espacios existentes, además de la observación de la degradación de la vacuola formando un apilamiento característico, también observado tanto en Pistacia lentiscus (Reig-Armiñana et al., 2004) como en Pinus halepensis (García-Breijo, comunicación personal), y con un grado de afectación mayor que el mostrado en el patrón de degradación.

El efecto del impacto continuado durante más de un año de crecimiento refleja una alteración en la lámina media que favorece la desorganización de los parénquimas en empalizada y lagunar, así como un aumento de vesículas dentro del contenido vacuolar del parénquima lagunar como se puede observar en las secciones semifinas teñidas con Azul de Toluidina.

En las muestras tomadas en este emplazamiento no se advierte una pérdida significativa de células parenquimáticas. Tampoco se observa un descenso en la actividad clorofílica, pues la tinción con Azul de Anilina examinada con microscopio de fluorescencia muestra que hay cloroplastos que serían fotosintéticamente activos. El tejido que presenta mayor grado de afectación es el floema, debido a una acumulación de calosa en los elementos floemáticos.

\section{Sierra de las Nieves (1100 $\mathrm{m}$. de altitud)}

Encontramos cómo a nivel del parénquima lagunar se ha producido desestructuración del tejido y pérdida de células parenquimáticas, dejando unos espacios entre sí, especialmente patentes bajo las cámaras subestomáticas de la cara adaxial. Estos estomas presentan por debajo un volumen muy reducido y el intercambio de gases y vapor de agua estaría muy limitado si se compara con los estomas de la cara abaxial.

Las secciones teñidas con Lugol muestran la presencia de gránulos de almidón en hoja de primer año, lo que contrasta con una hoja que, por su estadio del desarrollo, debiera tener un metabolismo activo de sus reservas.

El patrón de comportamiento es similar en acículas de segundo año, pese a que la localización del emplazamiento está alejada respecto al de la muestra de la Sierra Bermeja. Hay una intensa pérdida de células tanto del parénquima en empalizada como del parénquima lagunar. Las células de la vaina, pese a tener un contenido celular de color claro, muestran en sus paredes síntomas del efecto de los fotooxidantes, al presentar una tonalidad violácea. En las células xilemáticas no se observa alteración en su estructura, mientras que las células floemáticas, sobre todo cuanto más alejadas están del cambium vascular, presentan un mayor grado de aplastamiento y obliteración de la luz celular, así como la aparición de paredes con sinuosidades que no se observa en secciones realizados en plantas sanas.

\section{Sierra Bermeja (1180 m. de altitud)}

En acículas de primer año, las epidermis presentan alteración en la pared celular, con un cambio de coloración de las tinciones con Azul de Toluidina en la pared primaria en las zonas donde contacta con el aire, mientras las paredes radiales y tangencial externa, al presentar mayor unión entre sus células y la presencia de la cutícula, no muestran dicha alteración. Los tejidos parenquimáticos, tanto lagunar como en empalizada, muestran alteraciones significativas en sus paredes. Destacamos la observación de espacios en el parénquima en empalizada, que debieran estar ocupados inicialmente por 
células de este tejido, o en muchos casos células en pleno proceso de degeneración, diminuyendo la efectividad de los procesos en dicho tejido. Las células epidérmicas y subepidérmicas adyacentes a los espacios dejados por la pérdida de tejido, muestran claros signos de alteración en su membrana celular, aunque todavía no en su contenido (fig. 4A).

Cuando se observan hojas de dos años de edad, los procesos de detoxificación de la planta no pueden hacer frente al efecto acumulado del ozono, produciendo inicialmente un proceso de degradación de la lámina media y después del citoplasma, observándose una desorganización del vacuoma en unidades más pequeñas y apiladas, para producirse posteriormente un proceso de lisis celular, generando espacios donde las células debieran formar un mosaico. La epidermis presenta células con citoplasma colapsado e intensamente teñido y la subepidermis tiene el engrosamiento de la pared celular, obliterando la luz. Las células del tejido parenquimático adyacente se alteran, se observan numerosos fenómenos de lisis celular y las células adyacentes presentan deformaciones en la pared y un contenido irregular con la formación de microgotas hacia el exterior (fig. 4B).

\section{Sierra de las Nieves (1350 $\mathrm{m}$. de altitud)}

No se aprecia la misma cantidad de daño que en las poblaciones analizadas con anterioridad. Epidermis y subepidermis presentan pared celular delgada, con el contenido de la vacuola claro, con la formación de microgotas en algunas de las células del parénquima lagunar, y núcleos en interfase bastante voluminosos. El parénquima en empalizada presenta células que debieran mostrar una longitud mayor a la anchura, siendo aquí bastante irregulares en forma, y similares en tamaño a las células subepidermicas del haz y a las de la epidermis. Las secciones teñidas con Azul de Toluidina reflejan que la cutícula y las paredes primarias, sobre todo en las células de guarda del los estomas en el envés, muestran una tonalidad rosada, síntoma del efecto de los fotooxidantes sobre la lámina media y la pared primaria, pese a que no se vea tanto impacto a este nivel en las paredes primarias de las célula del parénquima lagunar.

En acículas de segundo año, la cutícula no presenta alteraciones significativas, tampoco la epidermis del haz, del envés y la subepidermis, en las zonas donde aparece este tipo celular. Por el contrario, los parénquimas tanto lagunar como en empalizada muestran falta de organización en el tejido, dejando espacios intercelulares más marcados en las células del parénquima esponjoso, donde además presentan formación de almidón alrededor de la vacuola central. Asimismo las células exhiben sinuosidades a nivel de la pared primaria. Los haces vasculares mantienen su estructura, sin embargo la tinción de secciones con Azul de Anilina y su observación bajo el microcopio con luz fluorescente remarca que la actividad de los cloroplastos no es demasiado elevada, ya que la emisión de estos orgánulos es poco apreciable.

\section{Parauta (1400 m. de altitud)}

El aspecto general de la sección transversal de las acículas muestra daños a nivel de epidermis y la subepidermis, con contenidos celulares fuertemente teñidos en los cortes semifinos, acorde a los resultados que se han obtenido en hojas con más de un año de vida. Las células del parénquima en empalizada presentan la misma situación, además de una clara desestructuración de las láminas medias y paredes primarias, que muestran una coloración diferente consecuencia del efecto de los fotooxidantes sobre ellas, apareciendo espacios intercelulares patentes. El parénquima esponjoso presenta degradación de las vacuolas y desestructuración de las paredes, con una elevada pérdida de células como consecuencia de la lisis celular que sufre este tejido.

Cuando las acículas son de dos años de edad, en el parénquima en empalizada se ha observado desagregación celular, pero sin llegar 

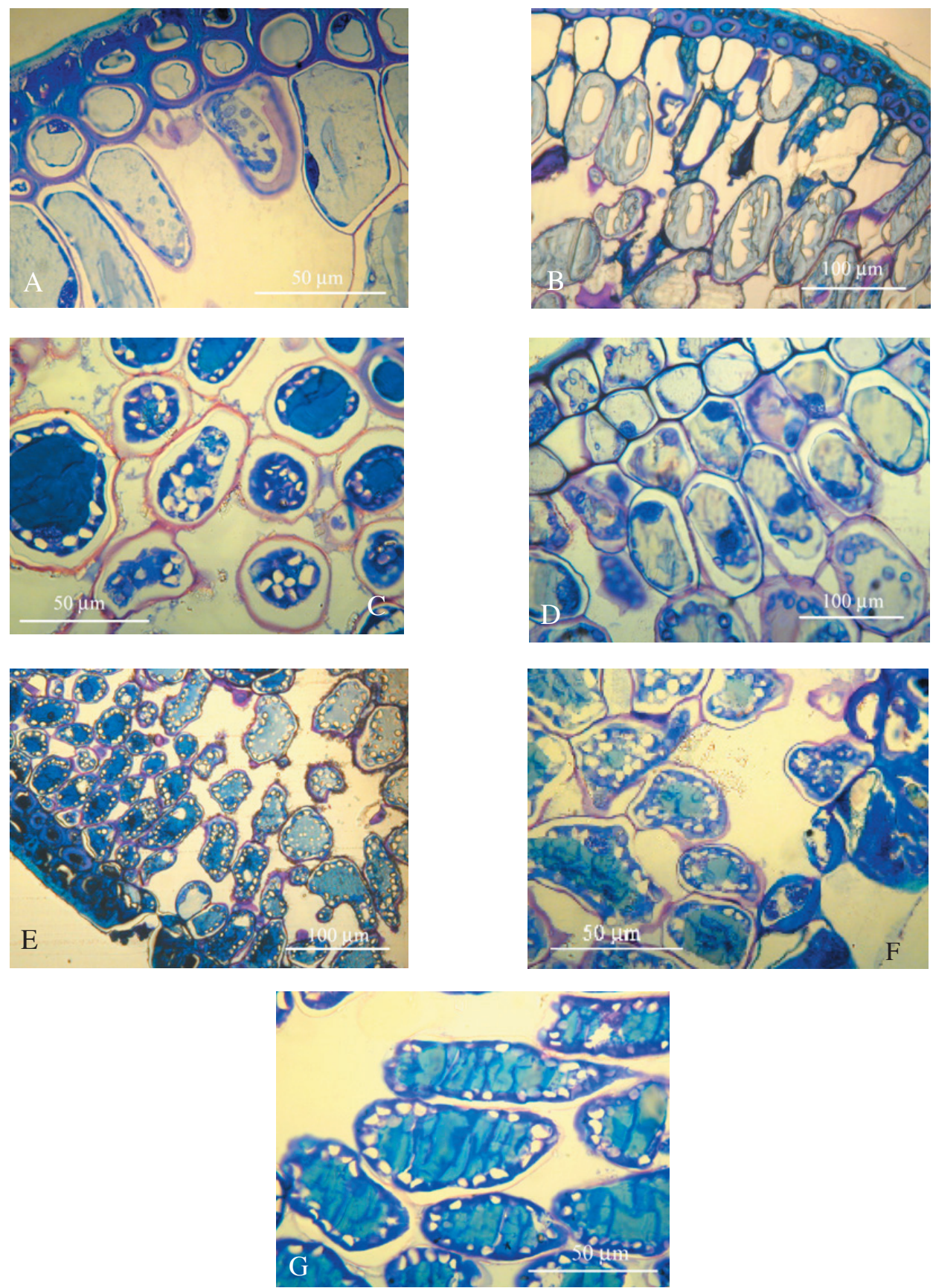

Figura 4. Muestra de daños según un gradiente altitudinal de muestras recolectadas en Sierra de las Nieves y Sierra Bermeja.: 1180 m, 1 año (A), 2 años (B); 1800 m, 2 años (C); 1500 m, 1 año (D), 2 años (E); 1700 m, 1 año $(F), 2$ años $(G)$. 
a una pérdida de células apreciable. A nivel del parénquima lagunar, las láminas medias y las paredes primarias se tiñen con el colorante Azul de Toluidina con una coloración rosado-rojiza. Las células aparecen con formas esféricas, nuevamente dejando espacios intercelulares, pero sin llegar a una pérdida de células (fig. 4C).

\section{Sierra Bermeja (1450 m. de altitud)}

La cutícula de las planta no presenta alteraciones estructurales, sí se encuentran en la epidermis adaxial, cuyas paredes celulares muestra una coloración rosada debido a la oxidación de la lámina media y pared primaria por efecto del ozono, sin mostrar alteraciones dentro del contenido celular, lo que evidencia que los efectos del gas no han atravesado la barrera de la pared celular. A nivel de parénquima en empalizada encontramos una situación menos notable, destacando que el tejido no se organiza en una empalizada regular, sino que aparecen intercaladas células, con una longitud mayor al doble de la anchura, con otras que presentan aspectos y tamaños irregulares sin encontrar en zonas donde se pasa de una subepidermis monoestratificada a biestratificada. El parénquima lagunar presenta grandes espacios intercelulares así como células con paredes sinuosas y angulosas. El contenido celular muestra síntomas de un inicio de degradación de la vacuola central y la formación de microgotas que serán vertidas con posterioridad.

La endodermis forma un tejido continuo, así como el tejido de transfusión. El haz vascular que se encuentra en su interior, muestra una estructura de tejido no afectado. En esta localidad el efecto acumulado en las hojas que tienen más de un año es significativamente superior al de las hojas de primer año. Las células epidérmicas aparecen con una afectación muy destacada, desfigurando la estructura y el contenido en este tejido, mostrando un continuo degradado donde es difícil distinguir una célula de la adyacente. Las células del parénquima en empalizada próximas a los estomas en la cara adaxial, presentan alteraciones en su contenido celular similares a las de las células epidérmicas, mientras que el resto del tejido parenquimático muestra una separación y aparición de sinuosidades entre las láminas medias de las células iniciando espacios intercelulares en un tejido que debiera ser compacto y sin espacios. El contenido celular se tiñe llamativamente con la tinción de Azul de Toluidina.

El parénquima esponjoso presenta células de diferente tamaño y estructura irregular, con láminas medias y paredes primarias con una tonalidad indicadora del efecto de fotoxidantes y un contenido en el que se observa claramente la formación de microgotas de distinta índole y un inicio en la desestructuración del núcleo, posiblemente entrando en un proceso de muerte celular en un periodo de tiempo no demasiado alejado.

A nivel de haz vascular, el floema tiene una luz celular prácticamente obliterada y las paredes celulares de este tejido están colapsadas y presentan una compresión y aplastamiento de las células, que dificulta el paso de sustancia elaboradas a través de ellas.

\section{Sierra de las Nieves (1500 $\mathrm{m}$. de altitud)}

Se puede observar que en las muestras a esta altura la cutícula, así como la epidermis y la subepidermis presentan escasas alteraciones. El contenido celular del parénquima en empalizada se asemeja al de las muestras control, así como las láminas medias y paredes primarias, que presentan menor grado de degradación, de manera que las células de este tejido dejan escasos o nulos espacios intercelulares entre ellas y no se aprecia con la tinción de Azul de Toluidina oxidaciones en las paredes (fig. 4D). La zona de transición muestra células que empiezan a dejar pequeños espacios intercelulares, con un contenido similar a las de las células del parénquima en empalizada y con paredes nuevamente sin daños significativos. El parénquima esponjoso tampoco presenta signos evidentes del impacto de ozono en acículas con crecimiento durante 
el primer año.

En las hojas de su segundo año, no se aprecian alteraciones en la organización tisular. El metabolismo de las acículas cambia con respecto al de las hojas de primer año, observándose un contenido que se tiñe fuertemente con el colorante Azul de Toluidina (fig. 4E). La tinción con Azul de Anilina y su observación bajo el microscopio de fluorescencia indica que los haces vasculares muestran una organización tisular no alterada y que el floema presenta una estructura sin obstrucción de los vasos conductores.

\section{Sierra de las Nieves (1700 m. de altura)}

A esta altitud, el efecto de los fotooxidantes existe en baja medida, ya que se puede apreciar su impacto a nivel de las láminas medias y pared primaria que aparece ligeramente alterada en las células del parénquima en empalizada, presentando un contenido celular similar al de una hoja sana. En el parénquima lagunar los efectos son algo más acusados, mostrando ya deformación de las láminas medias y las paredes primarias, y el contenido celular presenta alteraciones sin llegar en estos momentos a una pérdida celular por desestructuración de su contenido (fig. 4F).

El efecto del ozono en bajas concentraciones y durante tiempo prolongado no ofrece grandes alteraciones en la anatomía foliar, sin embargo a nivel celular se puede observar una alteración en las láminas medias y en las paredes primarias, tanto del parénquima en empalizada como en el parénquima lagunar. En hojas que tienen más de un año, el metabolismo produce una serie de sustancias que se tiñen con el Azul de Toluidina en diferentes tonalidades, así como gránulos de almidón que no se tiñen con este colorante acuoso (fig. 4G). Las muestras tratadas con la solución de Lugol indican que esta sustancia es almidón.

Los haces vasculares no presentan daños apreciables, pero se observa bajo luz fluorescente y tinción con Azul de Anilina que la cantidad de cloroplastos está reducida si se compara con una hoja no afectada por ozono de las mismas características.

\section{Estudio de las superficies foliares con Microscopia Electrónica de Barrido}

En todas las muestras estudiadas se observan acumulaciones de materiales que pueden llegar a obturar los estomas, que no son observables en las preparaciones para microscopio óptico, pues son eliminados durante el procesado. En ninguna de las muestras estudiadas se ha podido observar el aspecto cristalino de las ceras epicuticulares, tal vez sea debido al envejecimiento acelerado por el ozono y por ello la estructura preponderante es amorfa (Kinunnen et al., 1999, Piercy et al., 1994). En la población a menor altitudes (figura 5A), no se presentan modificaciones destacables de la cutícula. Los daños más fuertes son observados en la población de Parauta (Figura 5B), donde se aparece una gran cantidad de materiales depositados y daños por degradación y agrietamiento en la cutícula. A mayores altitudes (Figuras $5 \mathrm{C}$ y D) los daños cuticulares observados son escasos y presentan mayor obliteración de los estomas por deposición de materiales.

\section{DISCUSIÓN Y CONCLUSIONES}

Después de comparar los daños producidos en cámaras OTC y las muestras tomadas en campo podemos afirmar que el ozono produce diversos efectos en las acículas de Abies pinsapo, que en parte coinciden con una senescencia acelerada. Algunas de estas alteraciones son comunes a las observadas en otras especies estudiadas, especialmente en Pinus halepensis, Pinus uncinata, Pinus cembra, Picea abies (Kainulaien et al., 2000, Soda et al., 2000; Vollenweider \& Günthardt-Goerg, 2005), primero se acumula almidón en las células del parénquima y después los amiloplastos sufren un proceso de degeneración. Las vacuolas, con denso 

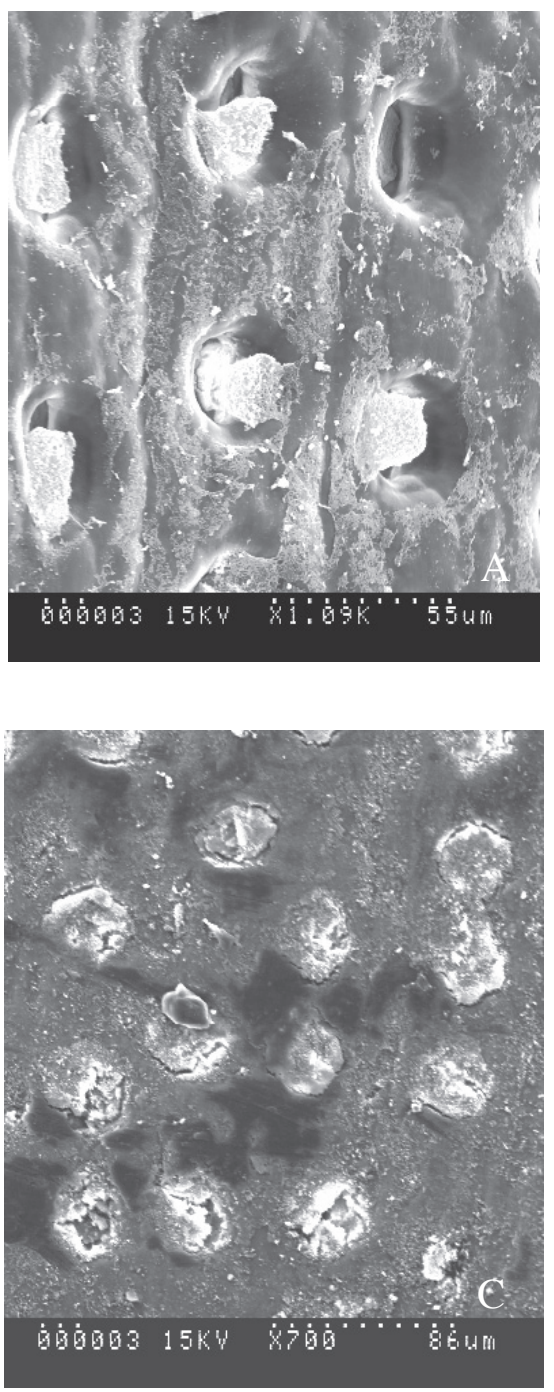
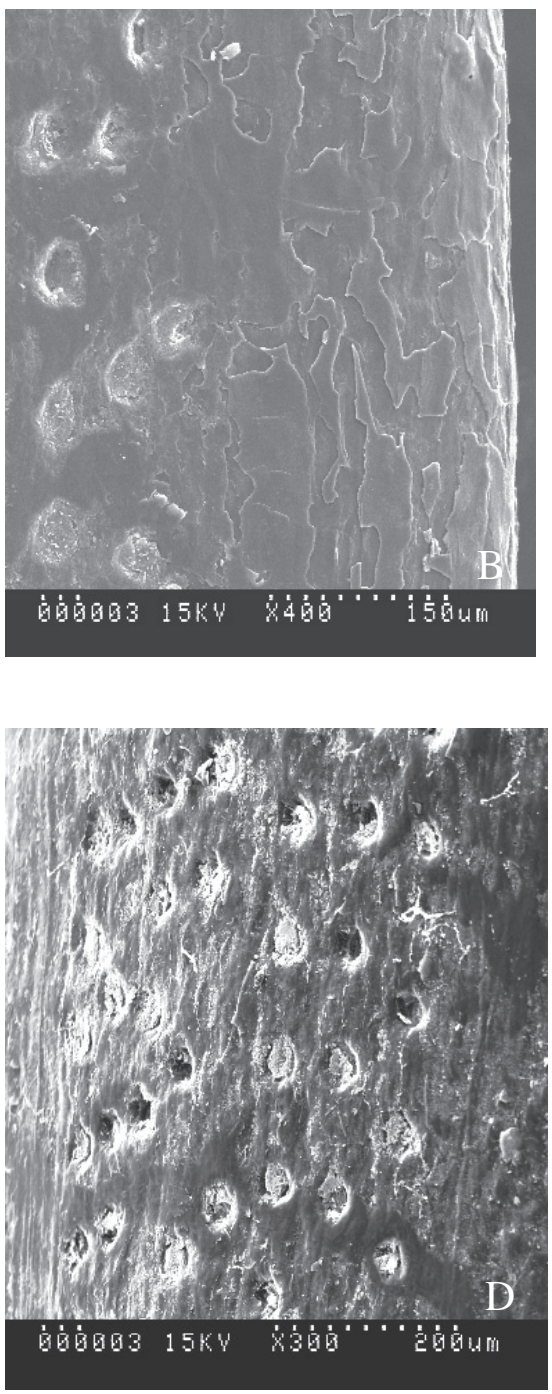

Figura 5: Muestras de Microscopio Electrónico de Barrido siguiendo un gradiente altitudinal: Sierra Bermeja (A); Parauta (B), Los Reales Sierra Bermeja (C), Puerto de los Quejigales (D).

contenido en taninos y fenoles (Peltonen et al., 2005), se retraen en el interior celular y aparecen claramente despegadas de la zona externa y con bandeado interior, así como alteración de estos materiales por su efecto antioxidante (Moss et al., 1998). Como en Pistacia (Reig Armiñana et al., 2004), también se producen microgotas en las paredes (Pääkkönen et al., 1998), y aumentan los espacios intercelulares, y las célula adquieren contornos muy sinuosos y angulares, especialmente en las cercanías de las cámaras subestomáticas. En el floema aumentan los acúmulos de calosa, disminuyendo la funcionalidad de este tejido $\mathrm{y}$, finalmente, se 
produce su colapso.

Todas estas alteraciones tienen implicaciones fisiológicas y funcionales para la planta, y son coherentes con diversos estudios (Gravano et al., 2004, Vollenweider \& Günthardt-Goerg, 2005) que ponen de manifiesto que algunas plantas que crecen bajo concentraciones de ozono elevadas, presentan una menor asimilación de $\mathrm{CO}_{2}$, ya que se produce una disminución del tejido asimilativo (por aumento de los espacios intercelulares) y de los cloroplastos funcionales; asimismo se detecta una pérdida importante en la carga floemática, lo que vendría explicado por los grandes acúmulos de calosa en los vasos. En diversas especies se ha detectado también que el ozono produce un aumento de la relación entre la biomasa de la parte aérea de la planta y la parte subterránea.

Si bien los daños no son iguales en todos los ejemplares, analizando los datos en las dos poblaciones de Abies pinsapo encontramos diferente comportamiento. En los individuos de la Sierra Bermeja que se ubican a 930, 1180 y 1450 metros sobre el nivel del mar se manifiesta que el efecto del ozono sobre los tejidos es en un grado elevado ya en hojas de primer año en todas las muestras, y que la presencia en el tiempo afecta, además, de manera visible a los tejidos una vez las acículas están en su segundo año de vida. Los efectos se ven dramáticamente incrementados a medida que se aumenta en altitud, de manera que las muestras que se tomaron a mayor altitud, presentaban en sección daños internos irreversibles con muerte celular en sus tejidos.

Los individuos de los cuales se han tomado muestras en la Sierra de las Nieves se encontraban en las siguientes altitudes: 1100, $1350,1400,1500$ y 1700 metros sobre el nivel del mar. En ellos se observa que desde las cotas más bajas, existe un impacto del ozono, mostrando signos de un daño moderado, sin llegar a la muerte celular, aunque sí mostrando una anatomía senescente en hojas en su primer año, con un crecimiento correspondiente a esa etapa, pero que mostraba claramente una fisiología de planta en etapas finales de su vida, con gran acumulación de almidón.

A medida que se aumentan las cotas en altitud, se observa que pese a existir daños la planta puede mantener su actividad celular, no llegando a su óptimo, pero superando la crisis producida por el impacto del ozono. Todos estos daños siguen un gradiente altitudinal, condicionado por la topografía del área.

\section{BIBLIOGRAFÍA}

ARISTA, M., F.J. HERRERA MALIANI \& S. TALAVERA LOZANO -1997- Biología del pinsapo . Ed. Consejería de Medio Ambiente, Junta de Andalucía.

BRUNDRETT, M. C., B. KENDRICK \& C. A. PETERSON -1992- Efficient lipid staining in plant material with sudan red 7B or fluoral yellow 088 in polyethylene Glycol-Glycerol. Biotechnic \& Histochemistry 67: 111-116.

CUEVAS, E., J. M. SANCHO \& A. REDONDAS -1996- Investigación y programa de medidas del ozono troposférico en el observatorio de vigilancia atmosférica de Izaña (INM). Física de la Tierra 9: 67-106.

FISHMAN, J., A. E. WOZNIAK, \& J. K. CREILSON -2003-Global distribution of tropospheric ozone from satellite measurements using the empirically corrected tropospheric ozone residual technique: Identification of the regional aspecs of air pollution. Atmos. Chem. Phys. 3: 893-907.

GRAVANO, E., F. BUSSOTI, R. STRASSER, M. SCHAUB, K. NOVAK, J. SKELLI \& C. TANI -2004- Ozone symptoms in leaves of woody plants in opent-top chambers: ultrastructural and physiological characteristics. Physiologia Plantarum 121: 620-633.

GÜNTHARDT-GOERG, M. S. \& P. VOLLENWEIDER -2007- Linking stress with macroscopic and microscopic leaf response in trees: New diagnostic perspectives. Environmental pollution 147: 467-488.

JOHANSEN, D. A. 1940. Plant microtechnique. McGraw- Hill Book Company. London.

KAINULAIEN, P., J. UTRIAINEN, J. K. HOLOPAINEN, J. OKSANEN \& T. KOLOPAINEN 
-2000- Influence of elevated ozone and limited nitrogen availabitlity on conifer seedlins in an open-air fumigation system: effects on growht nutrient content, mycorrhiza, needle ultrastructure, starch and secondary compounds. Global Change Biology 6: 345-355.

KINNUNEN, H., S. MANNINEN, R. PEURA, K. LAAKSO, \& S. HUTTUNEN -1999 - SEMEDS image analysis as a tool for scoring the epicuticular wax tube distribution on Pinus sylvestris needles - evaluation using a UV-B field experiment.Environmental and Experimental Botany 42: 173-180.

MOSS, D. M., B. N. ROCK, A. LINN-BOGLE \& J. BILKOVA -1998- Anatomical evidence of the development of damage symptoms across a growing season in needles of red spruce from central New Hampshire. Environmental and Experimental Botany 39: 247-262.

PÄÄKKÖNEN, E., M. S. GÜNTHARDT-GOERG \& T. HOLOPAINEN -1998-Responses of leaf processes in a sensitive birch (Betula pendula Roth) clone to ozone combined with drought. Annals of Botany 82: 49-59.
PELTONEN, P. A., E. VAPAAVUORI \& R. JULKUNEN-TIITTO -2005-Accumulation of phenolic compounds in birch leaves is changed by elevated carbon dioxide and ozone. Global Change Biology 11: 1305-1324.

PERCY, K.E., CAPE, J.N., JAGELS, R. and SIMPSON, C.J. Editors, 1994. Air Pollutants and The Leaf Cuticle, NATO ASI Series 36 SpringerVerlag, Berlin, pp. 113-121.

REIG-ARMIÑANA, J., V. CALATAYUD, J. CERVERÓ, F. J. GARCÍA-BREIJO, A. IBARS \& M. J. SANZ -2004- Effects of ozone on the foliar histology of the mastic plant (Pistacia lentiscus L.). Environmental Pollution 132: 321-331.

SODA, C., F. BUSSOTI, P. GROSSONI, J. BARNES, B. MORI \& C. TANI -2000-Impacts of urban levels of ozone on Pinus halepensis foliage. Environmental and Experimental Botany 44: 69-82.

VOLLENWEIDER, P. \& M. S.GÜNTHARDTGOERG -2005- Diagnosis of abiotic and biotic stress factors using the visible symptoms in foliage. Environmental Pollution, 2005 137: 455-465. 